\title{
¿COCINAR HIZO AL HOMBRE?
}

\author{
José MANUel GÓmez-Tabanera
}

Una de las más debatidas y apasionantes cuestiones, que puede formularse tanto el antropólogo como el arqueólogo es la planteada por las primeras artes culinarias, es decir el problema de la primera cocina y sus posibles consecuencias etiológicas, fisiológicas y culturales en el primate humano desde su descubrimiento y adopción. Por lo general no suele ser tratado o abordado en los textos, quizás por el rigor que exige su discurso y porque los mismos especialistas parecen haberse dado perfecta cuenta de las dificultades que entraña, ante la escasez de los documentos existentes, que por lo general sólo pueden referirse a la que podríamos denominar "prehistoria del fuego", al estudio o análisis de determinados documentos óseos, que puedan brindar ciertos yacimientos de la Edad de Piedra, incluido quizás algún utillaje, algún vestigio coprolítico y de estructuras a identificar, como restos de hogares, hornos, etc. y poco más. El tema, sin embargo, me ha venido preocupando, moviéndome a la reflexión, tras la lectura y cuidadosa relectura crítica de un libro de título pretencioso "Cocinar hizo al hombre" (Ed. Tusquets, Barcelona, 1980) obra del biólogo marxista Faustino Cordón, que ha alcanzado cierta difusión entre el público culto, pese al casuismo de sus planteamientos, que en cierta medida se nos antojan tan obsoletos como los que hace ahora más de un siglo se hizo F. Engels al escribir "El papel del trabajo en la transformación del mono en hombre" (Die Neue Zeit, 44, año XIV. 1895-1896, t. 2, págs. 545-554). De aquí que haya tenido la idea de revisar alguna de las cosas, que sobre las primeras artes culinarias, pueden ocurrírsele a un antropólogo o a un prehistoriador un tanto al día de la realidad paletnológica, desechando tópicos, lugares comunes, fantasías e incluso tonterías que más de uno, puede decir cuando se abordan cuestiones a tontas y a locas, sin una información previa, y con grave riesgo de una bien cimentada fama adquirida en la circunspección demostrada en la exposición de otros saberes.

Dado que parece obvio que los orígenes de las artes culinarias habría que buscarlos en los saberes adquiridos en una técnica muy particular aprendida por el género Homo en un momento concreto de su vida como especie, que es capaz de incorporar a su acervo cultural, pero que, indudablemente, no pudo adquirirse sin un conocimiento adecuado de las propiedades del fuego, - al que relativamente 
ha llegado a dominar-, como transformador de ciertas propiedades de las materias orgánicas que le sirven cotidianamente de sustento, parece lógico pensar que la cocina no hizo al hombre, aún cuando subrayemos la importancia que tal conquista cultural pudo tener en su desarrollo posterior, tanto desde un plano psíquico como físico, sin olvidar posibles derivaciones genéticas, que pudieran expresarse ya en el Homo sapiens, aparte de la cochura de los alimentos, además de hacerles más digeribles, trajera consigo una mejora de las condiciones metabólicas y de vida, al poner a su alcance la regularización dietética y un ritmo circadiano que en curso de los milenios pasarán a ser considerados como condicionantes del que hoy se entiende como comportamiento del Neantropo u hombre actual.

\section{Antes de la cocina: Economía mixta, solidaridad comunitaria y "primera Sociedad de abundancia"}

Por otra parte, en las concepciones evolucionistas que se impondrían en el último tercio del pasado siglo, primero tras las concepciones darwinistas, y después tras las elaboraciones de Tylor, quizás parezca demasiado extraño que se viera como un posible criterio de humanidad el conocimiento del fuego y su mantenimiento, incluso antes que la posesión de un lenguaje o cualquier tipo de útil en piedra y hueso. Idea ésta, que no pareció preocupar excesivamente al holandés Dubois, cuando descubre en Java y en 1891, los primeros restos del que habría de ser llamado Pitecanthropus erectus existente quizás 200.000 años atrás, pero que posiblemente, pudo influir hacia 1947, en plena euforia de hallazgos y taxonomización de los hombres mono que integran los llamados Australopithecos, considerados mucho más antiguos, para que al aparecer en Makapansgat (Africa del Sur) los restos de uno de ellos, que sería inicialmente bautizado Australopithecus prometheus, junto a vestigios de cenizas, se forjase toda una leyenda sobre el primer fuego controlado por el hombre, cosa que no resultó cierta. Años más tarde podría no obstante, atribuirse la primera utilización humana del fuego, detectada arqueológicamente, a la vez que a un Autrolopiteco que vivió hace más de un millón y medio de años, en el Africa Oriental, a un muy próximo pariente del hombre de Java: el Sinanthropus pekinensis, (hoy Homo erectus pekinensis), habitante de la Colina de los Huesos de Dragón (Chu-ku-tien) próxima a Pekín, y que de acuerdo con las observaciones in situ de H. Breuil y W. C. pei, hace medio millón de años, no sólo dispuso de hogares, sino también utilizaría el fuego tras su domesticación, para inaugurar las artes culinarias, e incluso técnicas de utilización que habrán de ser utilizadas por todos los Arqueantropos del Pleistoceno Medio, a quien la conquista del fuego les proporcionaría una seguridad hasta entonces desconocida en un mundo hostil, llegando quizás a la adquisición de particulares técnicas de producción y conservación, y que en la Europa Occidental, harán asimismo suyas, los hombres de Achelense Medio de Torralba (Soria) y Atapuerca (Burgos) en España; Terra Amata (Niza) La Escala (Bocas del Rodano) en Francia; Vërteszollos en Hungría; Swanscombe y Hoxne en las Islas Británicas... datándose a partir del interglaciar Mindel Riss. 
Tales evidencias con el progreso alcanzado en el conocimiento de los orígenes humanos no acabarían pese a todo por contentar a los especialistas. Ante lo contrario... Hasta el punto de no quedar tranquilos hasta poder indagar la posible existencia humana antes de la conquista del fuego y del primer cocinado, lo que les llevará nuevamente, si no al mundo de los Austrapolithecos africanos, al del Homo habilis, al parecer "el primer hombre" que cabe considerar como tal, preocupándose por su dieta, hábitos comunitarios y unos societarios relacionados con la alimentación, y que, tarde o temprano habrían de influir en aquéllas que pudieran imponerse en la utilización del fuego.

Se abriría así, hace apenas un decenio, una investigación apasionante, en Africa Oriental a cargo de los primatólogos americanos Robert Harding y Shir ley Strum, tras la observación de ciertas bandas de babuinos y su conducta social, investigaciones cuyos resultados serían completados con los obtenidos por el finado R. Ardrey, aunque no sin ciertas reservas, y, más tarde por Nancy Tanner y Adrianne Zillman, en torno al papel de las hembras, entregadas a la recolección de diversos productos animales y vegetales para su consumo a posteriori, complementando la aportación proteínica de los machos carroñeros y configurando así un esbozo de primera economía mixta. Observaciones anteriores de G. Schaller y G. Lowther, en el Serengeti, en torno a las técnicas de recuperación de la carne, procedentes de los despojos de los grandes carniceros y el "consumo diferido" que se hacía de la misma, solidariamente y en comunidad, parecen pues señalar a una clara división del trabajo, típicamente humana, no muy diferente quizás a la hoy existente entre los Kung y otros recolectores - cazadores pertenecientes al mundo primitivo y que incluso permitiría de acuerdo con la expresión consagrada por Marshall Shalins una primera "sociedad opulenta", que contaría incluso con utillaje adecuado a las labores a realizar y en las que una especie de "altruismo recíproco" empezaría a emerger como primer criterio de humanidad y que a la larga traería la aparición de "emociones como la simpatía, la gratitud, la culpabilidad y la indignación moraln ( $R$. E. Leakey y R. Lewin) y que memorizadas o proyectadas al futuro en razón de la inteligencia/consciencia que pronto será utilizada en la utecnología de subsistencia” e incluso en la consagración del canibalismo a la vez que la invención de una economía alimentaria basada en la utilización del fuego, mediante diversos expedientes, cuya consecuencia más trascendental sería un mejor aprovechamiento de las pitanzas por el grupo mediante la transformación de los productos alimentarios, de origen animal o vegetal, mediante la cocción, que no sólo permitiría su más prolongada conservación sino hacerles más nutritivos o gustosos a liberarles de aminoácidos.

\section{En torno a una tipología de los más antiguos hogares conocidos}

Ha sido el etnólogo/prehistoriador francés, A. Leroi-Gourhan el primer estudioso que, con sus planteamientos metodológicos, ha permitido abordar el estudio de los primeros Hogares conocidos ejecutados en el alba de la Humanidad y que 
fueron utilizados para las primeras prácticas culinarias. Hasta que planteamientos, relativamente recientes - se iniciaron en 1973-, un cursillo del College de France con la mayoría de los investigadores que se interesaron en el tema, apelaban para una posible resolución, en los presuntos datos que parecía proporcionar el llamado comparativismo etnográfico. No obstante Leroi-Gourhan para sus planteamientos partirá de otras bases, teniendo en cuenta los resultados que han venido brindando en las últimas décadas. Por un lado, la llamada a) Prehistoria tipológica, y, por otro, b) prehistoria etnológica. De aquí, que pueda abordarse la cuestión bajo dos proyecciones distintas: a) la que surge del estudio de las estructuras que van siendo conocidas en diversas excavaciones y prospecciones arqueológicas, independientemente de sus distanciamientos temporal o espacial. Así por ejemplo las evidencias encontradas en Shesowanja, Kenya, Africa Oriental y que permiten hoy hablar de la utilización "técnica" del fuego hace aproximadamente dos millones de años y quizá del primer hogar, sino por una Australopithecus robustus, a un Homo habilis o mucho más cerca de nosotros el habitat magdaleniense de Pincevent (circa 10.000 a. C.) o en de Arcy-sur-Cure (habitaciones en cueva en el Paleolítico Superior). En la proyección b) habría de tener en cuenta todas aquellas observaciones que cabe extraer del comportamiento "culinarion del conocimiento y estudio etnográfico de diversos pueblos cazadores y recolectores actuales, o a la vez que de todos aquellos que tenemos noticia con la Historiografía, viniendo a sumar decenas de millares de documentos, que por causas obvias sólo podrían ser procesados en parte.

Todo esto pues, nos pone ante la disyuntiva de abordar nuestro discurso dentro de una consideración tipológica de las estructuras que van siendo conocidas por diversos arqueólogos desde la institucionalización de la Prehistoria como ciencia, dejando de lado la cuestión muy aleatoria, muy discutible de que la misma elementalidad o simpleza de la estructura conocida o estudiada, abona la idea de una mayor antigüedad de la misma. La evidencia documental permite no obstante, hablar hoy por hoy, al menos de ocho estructuras que hubieron de contar muy tempranamente a la hora de elaborar las primeras técnicas culinarias. Son las siguientes:

1. La fogata u hoguera al aire libre. Utilizada desde la "domesticación" del fuego por los primeros homínidos que lo lograron, posiblemente en un estadio económico de cazadores recolectores, tuvo una utilización polivalente que iba desde su uso para cocinado hasta la protección nocturna. Aún hoy sigue vigente su uso, sobre todo en el medio rural y en contextos pastoriles.

2. El brasero de fosa o cubeta. De invención asimismo temprana, su utilidad estriba en la conservación de un fuego o vivaque, cubriendo las brasas o ascuas con cenizas. De acuerdo con técnicas diversas pudo hacerse transportable, siendo utilizado no sólo por gentes primevales de economía primaria que ejercitaban el nomadismo, en un ambiente en que el fuego era absolutamente necesario para enfrentarse a los rigores climáticos. En su estructura más elemental el brasero sigue siendo utilizado por "contemporáneos", aún en la Edad de Piedra, como los aborígenes australianos y los bosquimanos del Africa del S.W.

3. El hogar doméstico. Se presenta ejecutado en un lugar estratégico del habitáculo, casi siempre en el centro de una estancia o cámara principal. Esquemática- 

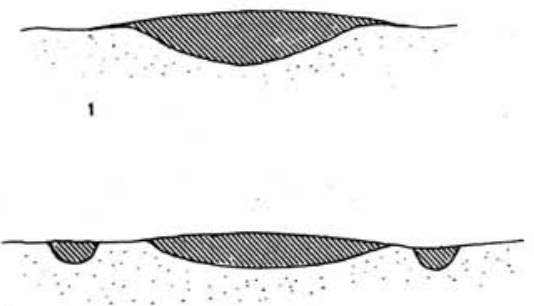

3

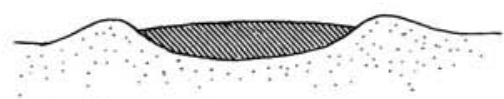

5
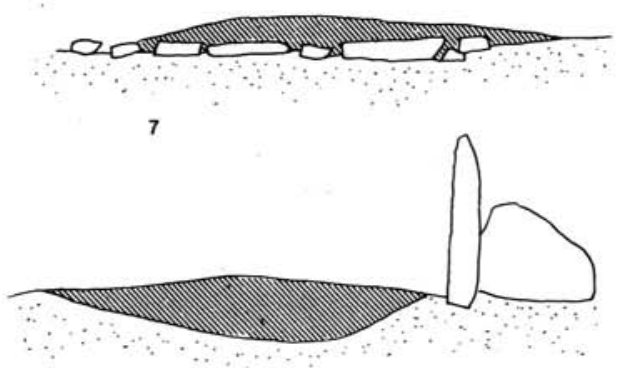

9

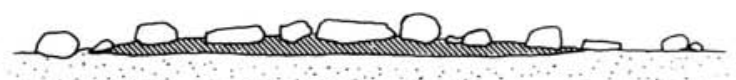

11
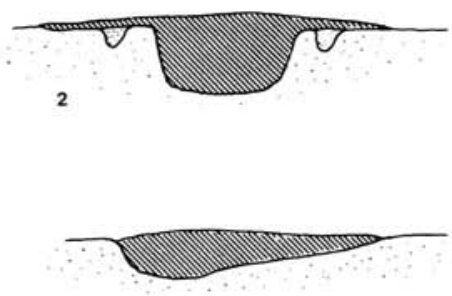

4

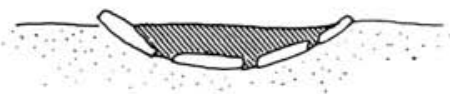

6
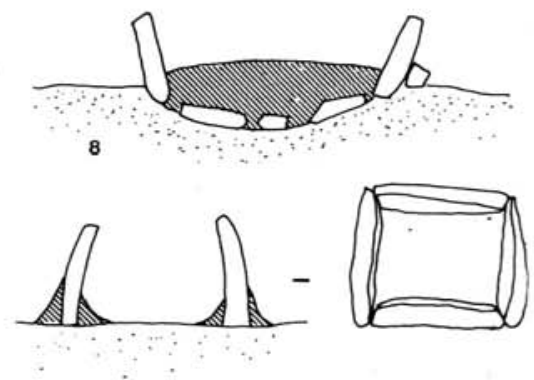

10

Esquemas con secciones de diversos tipos de hogares paleolíticos. 1. - Hogar elemental en cubeta; 2. - Hogar en cubeta de paredes verticales con depresiones laterales rellenas de tierra ( $\mathfrak{a}$ agujeros de soportes?); 3. - Hogar en cubeta con depresiones laterales rellenas de ceniza y de restos de carbón (¿cocción de alimentos?); 4. - Hogar en cubeta disimétrica (aleatoria); 5. - Hogar con un reborde en tierra; 6. - Hogar en cubeta empedrada; 7. - Hogar plano sobre lastras; 8. - Hogar construido con paredes y fondo en piedra; 9. - Hogar protegido mediante un ortostato; 10. - "Hogarn integrado por cuatro pequeños ortostatos; 11. - Hogar plano recubierto de plaquetas y guijarros, quizá para conservar el calor. Figura rayado el relleno de cenizas y restos de carbón y combustión. En puntillado suelo arqueológico (Según A. Leroi-Gourhan, 1973). 
mente, consta de tres piedras colocadas en un lugar plano del terreno, que sirven para retener ascuas y ceniza, y para soporte de los recipientes colocados sobre el fuego. En ocasiones, su construcción se atiene a un arquetipo basado en creencias arcaicas de raiz supranaturalista y presenta una base o fondo refractario.

Cuando se encuentra en cabañas sobre pilotes ó de materia vegetal se adoptan particulares técnicas de seguridad. Su invención ó adopción se sitúa en el Neolítico y entre las primeras culturas de aldea del Creciente Fértil ó los Balcanes.

4. El hogar con tiro o chimenea. De invención multifocal, surgió por perfeccionamientos localistas. Se caracteriza por llevar annexo una campana o conducto de humos, que hasta su adopción salían al exterior por intersticios de techumbres y paredes. En determinados ambientes adopta características especiales. Así en Yakutia (Siberia) y Kirguisia (Asia Central).

5. El brasero mueble. Neta derivación del 2 (Cf. supra). Consta de una especie de caja o recipiente aplanado, que llevan consigo los usuarios en los desplazamientos impuestos por una existencia nómada. Es corriente entre diversos pueblos siberianos, amerindios del N.W. En culturas antiguas se presenta confeccionado en terracota. Es utilizado aún por diversos pueblos de América del Sur (Aymara, Quechua, Uru, etc.).

6. Horno enterrado. (Horno natural o de tierra). Se desconoce su origen que, no obstante, cabe vincular a culturas de raíz paleomesolítica, siendo aún de uso corriente en el mundo oceánico. Se presenta generalmente tapizado de piedras planas utilizándose, casi siempre, combustibles vegetales, a los que se les ha unido hojas carnosas con objeto de "guisar" los alimentos. Llegan a tener grandes dimensiones y en diversas sociedades tribales son muy utilizados para la celebración de fiestas y agapes colectivos, llegando a contener cantidades ingentes de alimentos para su cocción o asado, incluso animales enteros, eviscerados y quizá rellenos. Un tipo similar de horno será asimismo usado por los antropófagos de Nueva Irlanda. Los hornos enterrados pueden funcionar continuamente, si se les alimenta durante horas e incluso días.

7. Horos de aire caliente. Las técnicas de utilización del mismo se basan en la experiencia lograda con tipos anteriores y otros hornos utilizados ya a partir del 8.500 B.P., con alfareros y herreros.

8. Cabañas sudatorias. Estas estructuras se inventan y utilizan aplicándo observaciones hechas sobre otros hornos y hogares, acción del fuego, posible producción de vapor etc. Surgen así las mismas con fines diversos, incluso ritual y medicamentoso. Sabemos de su utilización a partir del Neo-Eneolítico en numerosas culturas del Viejo Mundo, dando origen a las hoy llamadas saunas, pero también a cámaras de sahumerio, lustración y purificación. Algunos tratadistas han pretendido ver tal función en estructuras particulares que aparecen aldeas protohistóricas del N.W. de la Península Ibérica (cultura de los castros) y que en su mayoría cabe identicar como hornos comunales de panificación, aunque sin descartar alguna utilización extemporánea con dicho fin.

Naturalmente, esta clasificación podría hacerse mucho más minuciosa y compleja, teniendo en cuenta, sobre todo, las investigaciones que se han llevado a efec- 
to por diversos especialistas y en gran parte de la Ecumene, y entre las que revisten particular interés las investigaciones de C. Perles, en torno a los hornos paleolíticos de concretas regiones pre-urálicas de la URSS, y cuyo conocimiento ha permitido reconstruir y conocer hasta límites razonables, muchas de las técnicas de conservación y utilización del fuego, utilizadas por los cazadores y recolectores de la Edad de Piedra y que se ampliaron para la preparación de productos alimentarios, mediante técnicas culinarias diversas.

\section{Desde las técnicas post-venatorias y de preparación de los productos alimentarios destinados al consumo, a las técnicas propiamente culinarias}

Hoy, y pese a los avances logrados en el conocimiento del mundo prehistórico, se dan aún grandes lagunas referidas a concretas técnicas post-venatorias relativas al tratamiento de las piezas cobradas por los cazadores prehistóricos; conservación de carnes y pieles; primeros tratamientos del hueso, asta y otros despojos de sus piezas, preservación de diversas materias alimentarias animales y vegetales procedentes de la recolección, incluso marisquera, a la vez que un conocimiento que podamos considerar suficiente del régimen alimentario de los cazadores y pescadores de la Edad de Piedra, así como técnicas de preparación de alimentos para su posterior ingestión o absorción.

$\mathrm{Al}$ disponer de numerosos restos óseos de las especies animales aprovechadas, capturadas y consumidas por los hombres de la Edad de Piedra, y de las que nos dan razón la documentación paleontológica que presenta numerosos yacimientos y paraderos, se facilita la investigación dado que permite establecer no sólo gráficas de frecuencia, sino también de referencia de la fauna utilizada con fines alimentarios. No obstante, es fundamental poder diferenciar entre los restos provenientes del consumo o ingestión humana, de otros dejados por los depredadores naturales, merodeadores del paradero. Investigaciones sofisticadas, permiten muchas veces averiguar la estación o época en que se llevaron a efecto determinadas capturas y consumos a la vez que la edad media de los animales cazados y consumidos, su especie, raza o variedad. El análisis de coprolitos, ha permitido por otra parte extraer interesantes consecuencias.

No obstante, diversas investigaciones actuales hacen patente la desproporción que existe en concretos ámbitos, a la hora de usar y consumir determinadas especies, así como la utilización de productos "secundarios" (asta, marfil, etc.), haciendo pensar, independientemente de aquellos factores que han hecho posible su utilización económica, en la existencia a otros determinantes como pongamos por caso la ritualización de que pudieron ser objeto alguna de las especies utilizadas y consumidas (o partes concretas de las mismas, como por ejemplo los omoplatos que serán utilizados como soporte de grafismos de valor semiótico, sígnico o ritual). Ello no descarta determinadas interdicciones ó tabues sobre concretas especies en lo que se refiere a consumo alimentario. 
Independientemente de esto y antes de entrar en materia culinaria cabría preguntarnos también si a la hora de su aprovechamiento no se establecen diferencias entre las especies cazadas. Así, bóvidos y equidos pudieron simplemente nutrir necesidades de proteínas cárnicas, en tanto que especies como el ciervo o el reno pudieron ser cazados no sólo en virtud de su aprovechamiento cárnico sino también el de otras materias primas, a aportar a la economía comunitaria. Así, los productos derivados de sus astas, pieles y tendones, muy aprovechables a la hora de proporcionar armamento, utillaje, cordelería, etc. pero también objetos de proyección simbólica. La caza de animales peleteros, para su aprovechamiento concreto habría así, también, que tenerse en cuenta.

Trabajos experimentales llevados a cabo en el transcurso de los últimos años por L. Pfeiffer en Europa Central, seguidos por los de L. Henri-Martín y A. LeroiGourhan en Francia, y más recientemente por J. Altuna y el autor de este trabajo en España - ambos en investigación independiente-, quizá han contribuido a profundizar en detalle en torno a alguna de las técnicas post-venatorias utilizadas por el cazador prehistórico desollando y troceando la caza antes de proceder a su cocinado ó guisado. $\mathrm{El}$ animal suspendido "ad hoc», apiolado y eviscerado, será despellejado mediante técnicas y manipulaciones particulares, que se evidencian claramente en los estigmas y pequeñas improntas y laceraciones que quedan en los huesos de las extremidades, o junto a articulaciones y que se observan con diversas partes de su anatomía. Tales técnicas y otras parecidas siguen aún vigentes entre los pueblos cazadores actuales y nada impide que, por comparación, podamos reconstruir e imaginar su utilización entre los cazadores de la prehistoria. Así, tras la decapitación del tronco ó cuerpo sería seccionado en varios trozos, separadas las extremidades, que, a su vez se verán desarticuladas y troceadas. Los cortes que afectan a las articulaciones y a la región tibio-társica y que se aprecian por los estigmas que han quedado en ciertos restos óseos, son ejecutados con particular pericia. Vestigios de tales operaciones pueden notarse en falanges de bóvidos, equidos y cérvidos (ciervo y reno), entre los de otros animales y que se presentan como «restos de cocina” en concretos yacimientos paleolíticos. Así, son inconfundibles ciertas incisiones oblícuas que aparecen en el material óseo y que fueron ejecutadas en su día al separar tendones y músculos. Se aprecian también huellas de incisiones y cortes en los cráneos y en las sinfisis de las mandíbulas y sobre todo en las protuberancias que se forman en las zonas de nacimiento de las astas en el cráneo de los cérvidos. Sabemos incluso de huellas, incisiones y estigmas intencionados que se presentan en las costillas y entre éstas alguna rota nos hace pensar en el forzado de la caja torácica, a efectos de evisceración.

Tenemos pruebas evidentes de que ya en el Paleolítico Medio (horizonte musteriense), el hombre había adoptado métodos y procedimientos expeditivos para el troceo de la caza, desde el dislocamiento ó desgarramiento de las extremidades para su más fácil transporte hasta las más variadas fracturas óseas, incluyendo en las mismas desmembramientos ó desgajamientos y amputaciones. Ya en sus paraderos, con más tranquilidad que en el kill-site, por lo general a cielo abierto podría idear y desarrollar diversas técnicas post-venatorias y preculinarias con vistas al 


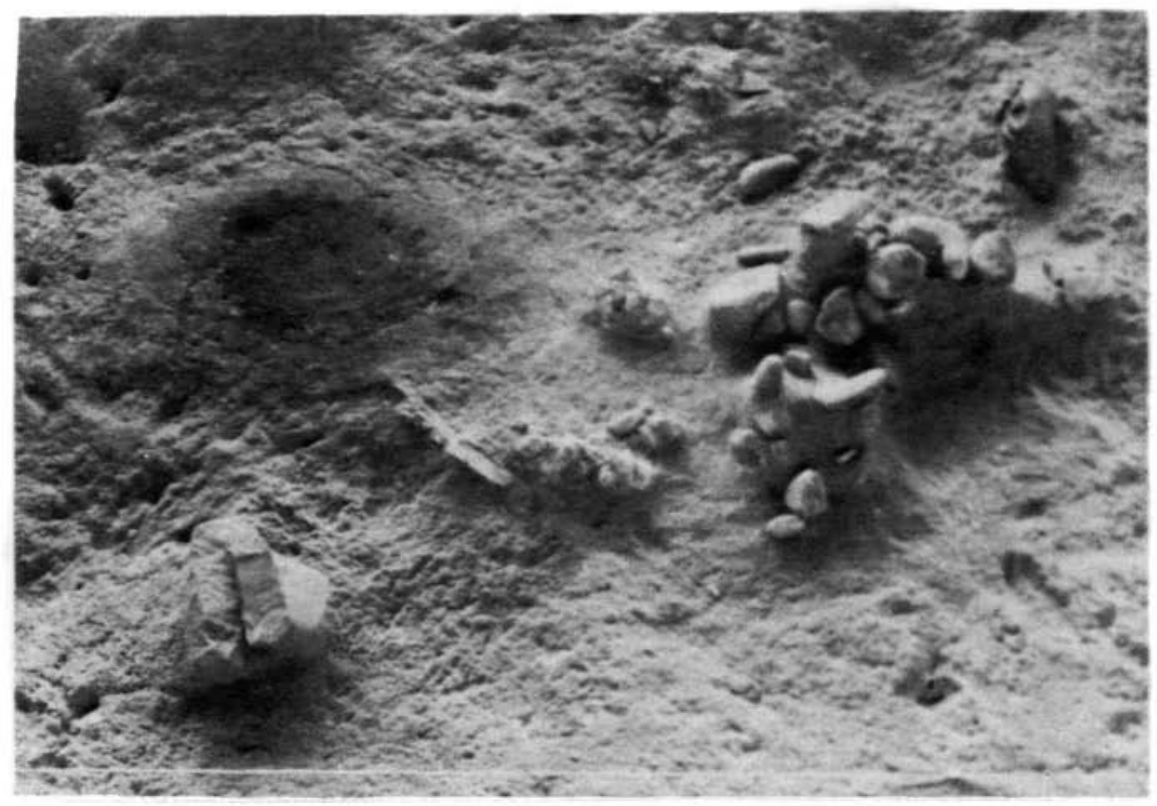

Vestigios de hogar en cubeta, encontrados en Terra Amata, Niza, a datar de acuerdo con $\mathrm{H}$. De Lumley en un horizonte de Mindel III (Según C. Perlés). 
aprovechamiento integral del alimento transportado, incluyendo la médula de los huesos, que pudo servir cuando no era viable su utilización alimentaria de combustible para sus lámparas de piedra ó de excipiente en el que habrá de llamarse "arte rupestre». La descarnadura se lograba con gran pericia, según cabe apreciar también por los cortes o incisiones ya indicados que se dan en los huesos y que nos hace pensar incluso en una posible especialización técnica por parte de alguno de los componentes del grupo, especialización que se hará precisa quizá en proyecciones artesanas del llamado "arte mueble». En este orden de ideas podía pensarse asimismo en otras especializaciones particulares, desde la adquisición de técnicas de conservación y preservación de los diversos alimentos mediante "adobo" o ahumado hasta la utilización de "pozos de nieve" para tal fin, tras la utilización y manipulación del fuego y su energía calorífica a la hora de transformación y "cocinadon de diversos alimentos y presas.

\section{Sobre la cocción alimentaria}

El cocinado o tratamiento culinario de los alimentos mediante el fuego, seguido de la invención del guisado de los mismos, constituye quizá una de las actividades humanas que, de acuerdo con lo expuesto en los inicios de este trabajo más repercusiones ha tenido, a nuestro juicio, en la evolución y progreso de la especie humana (en su patología), a la vez que en su desarrollo intelectivo. Aún cuando, como ya también se ha dicho, en Shesowja Kenya, se ha encontrado recientemente la más antigua evidencia conocida de fuego encendido por un homínido, y que en este caso concreto pudo ser quizá un australopithecino, artífice de los guijarros tallados hallados junto al mismo, tal descubrimiento, hoy por hoy sólo es utilizable a efectos de datación "post quem". Por otra parte, teniendo en cuenta ciertas características geológicas que presenta algunas regiones del Africa Oriental, que fueron asiento de primerizas humanidades - como el Great Rift Valley y concretas zonas de Etiopía-, quizá podía pensarse que los primeros intentos de cocinado pudieron surgir después de que los primeros hombres cataron diversos restos animales expuestos a la acción de un fuego forestal de origen casual, o a la acción de las aguas de una fuente termal; quizás un geiser, que consiguió un cocido natural, ablandando la contextura fibrosa de la carne, dotándola de un saber peculiar y haciéndola más digerible. De tales inicios, a un razonamiento deductivo a darse en los inicios del Paleolítico, de que con el calor del fuego podrían hacerse los alimentos cárnicos más duraderos, tiernos y digeribles, no creemos que se diera una distancia infranqueable para el primer hombre, capaz ya de relacionar el efecto con la causa.

Se impone no obstante una posible investigación en torno al origen de las posibles técnicas culinarias más arcaicas, conocidas por los cazadores de la Prehistoria y que, independientemente de la tipología de hogares u hornos ya propuesta o alguna paralela o similar, podría partir quizá del estudio analítico de los vestigios. En estos habría que diferenciar - siguiendo a C. Perles-, entre partes no consumibles de los alimentos y vestigios no destruidos por agentes naturales (químicos 


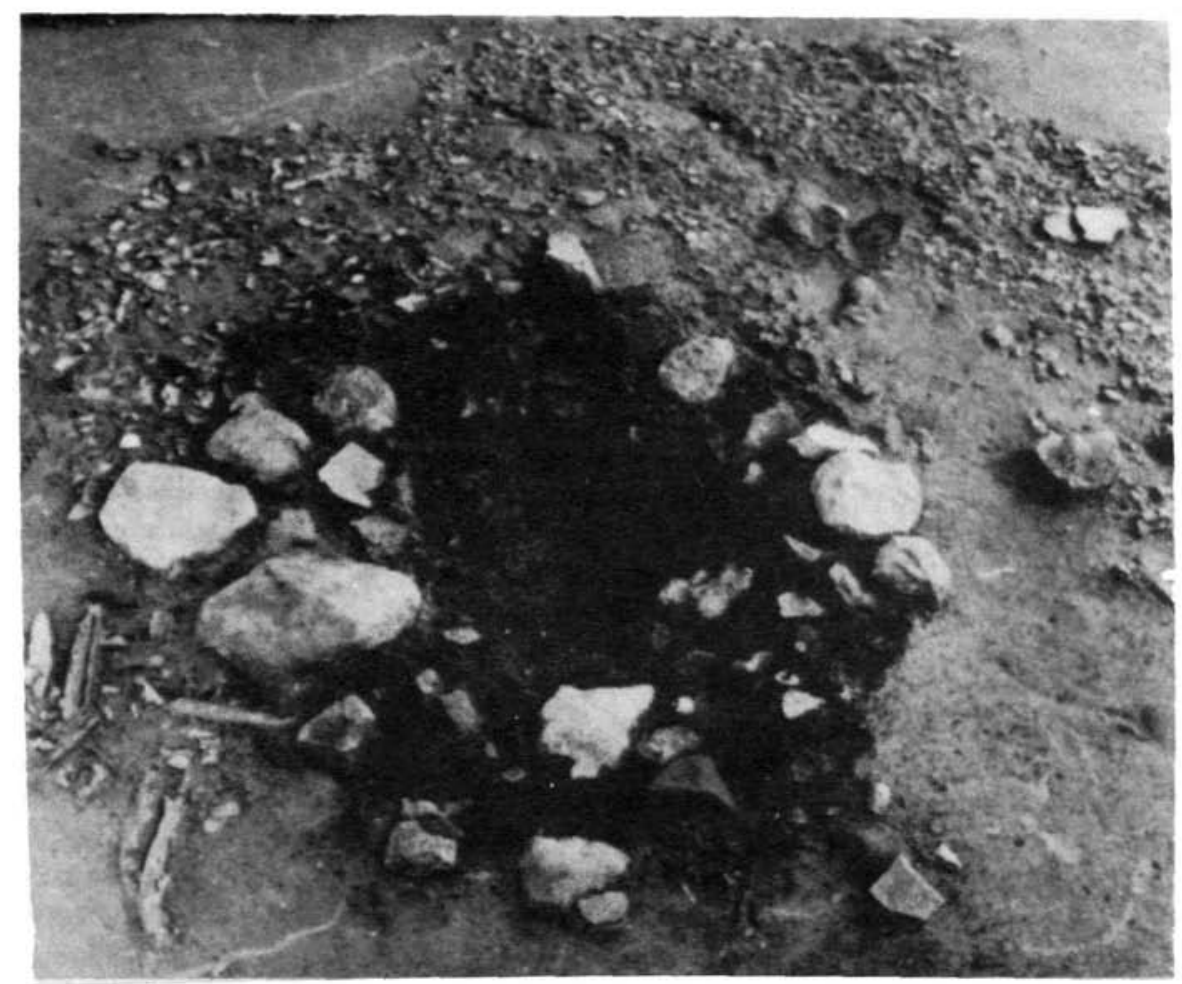

Fotografía oblícua de los vestigios de un hogar encontrado en la habitación V 105. Pincevent (Seine et Marne. Excavaciones bajo la dirección de A. Leroi-Gourhan).

o bacterianos, pero también depredadores). De acuerdo con dicha estudiosa, habríamos de partir no obstante, de dos tipos de alimentos: Los alimentos de tipo vegetal y los de origen animal. De los primeros apenas hay evidencias para poder afirmar taxativamente que pudieran ser objeto de técnica culinaria en el Paleolítico. Por lo que se refiere a alimentos de origen animal, pese a carecer de la evidencia de partes blandas, es obvio que han llegado hasta nosotros restos mineralizados, particularmente osamentas, en diversos estados de conservación y que nos permiten pensar en la utilización de varias técnicas culinarias.

Su uso es evidente, como se ha dicho a partir del Paleolítico Medio, del horizonte del Homo s. neanderthalensis. A este respecto podríamos recordar bastante documentación recogida en yacimientos bien conocidos. Así La Chapelle-aux-Saints, $\mathrm{y}$ otros yacimientos musterienses.

Diversos indicios parecen incluso demostrar que la técnica culinaria más antigua fue el asado. Cuando los huesos no se presentan quemados o calcinados, se puede incluso pensar en el conocimiento y utilización de otras técnicas culinarias como 
el cocido (la cocción), puesto asimismo en práctica por los cazadores paleolíticos, en consecuencia a particulares observaciones. Estas pudieron surgir tras notar que el caldeamiento a que pueden someterse ciertos objetos combustibles e incombustibles tienen un "punto límite" aprovechable. Así, los guijarros tras su contacto con el fuego dan lugar al fenómeno de conservación térmica, que les conviene durante algún tiempo autoradiantes de calor. Tal hecho fue observado, conocido y utilizado por el Homo erectus pekinensis, y después por el Homo s. neanderthalensis, con fines calefactores. En el Paleolítico Superior sin embargo tal observación pudo ser completada y los guijarros ser utilizados para el preparado o conservación mediante cocción de diversos alimentos de origen animal, incluidos huevos, mariscos y moluscos procedentes de la recolección. Para tal logro es posible que incluso fueran utilizados con tenedores de piel o corteza y cestos impermiebilizados en los que se contenían los alimentos a cocer, desde pequeños animales preparados, incluso mariscos simplemente inmersos en agua hasta trozos de carne, y que llevándolos a la ebullición tras introducir en el recipiente piedras en uso, pero de raíces milenarias, bien conocida y aun practicada por los indios de la costa N.W. de los Estados Unidos (Kwakiutl, Tsimshim, Tlingit, etc...). Técnica que no difiere por otra parte apenas de la utilizada hasta nuestros días por los pastores del País Vasco hispano-francés para hervir la leche con vistas a la elaboración de quesos, utilizando como recipiente el llamado kaiku - una especie de cubo de madera-, en el que se introducen guijarros candentes. Por otra parte no hay que descartar la cochura al vapor, variante intermedia entre el uso de piedras caldeadas y el horno enterrado, ya mencionado en nuestra tipología. En él los alimentos a preparar se disponen en una especie de cista junto con piedras candentes y a continuación todo el conjunto será cubierto o tapado con hojas o cueros, vertiéndose a través de los mismos y en la fosa cierta cantidad de agua que se evaporiza en contacto con las piedras. Procedimiento éste, en la prehistoria del guisado todavía utilizado hoy por ciertos pueblos oceánicos.

Todo esto parece demostrar que ya en la Edad de Piedra y desde momentos que no podemos precisar se conocían varias técnicas de cochura ó cocción de los alimentos factibles sin utilización de recipientes de cerámica o metal a inventarse miles de años después en un mundo postglacial y desconocidos en el Paleolítico. Muchas de estas técnicas nos son asequibles por el comparativismo etnográfico. Así, sabemos que en las islas Nicobar (Océano Indico) es corriente hervir líquidos utilizando recipientes de corteza que son expuestos directamente sobre el fuego. Técnicas parecidas siguen vigentes aún entre los Luba del Africa Central (antiguo Congo belga). Ello nos autoriza a pensar que durante el Paleolítico Superior, en toda la España Septentrional, Pirineos, Aquitania, Italia Septentrional y Europa Central pudo llegarse a la cocción directa sobre el fuego utilizando contenedores hechos ya de madera, ya de pieles o de tejidos tegumentarios, quizás las mismas entrañas o estómagos de ciertos animales. Al respecto y siguiendo el método comparativo, quizá podría servirnos de evocador paradigma-, aunque pertenezca a un horizonte mucho más reciente a datar sin embargo a unos 2.400 B. P. la vivaz descripción del griego Herodoto de Alicarnaso que nos describe cómo los bárbaros escitas sin disponer de calderos aciertan a cocer sus alimentos. Para ello introducen la carne 


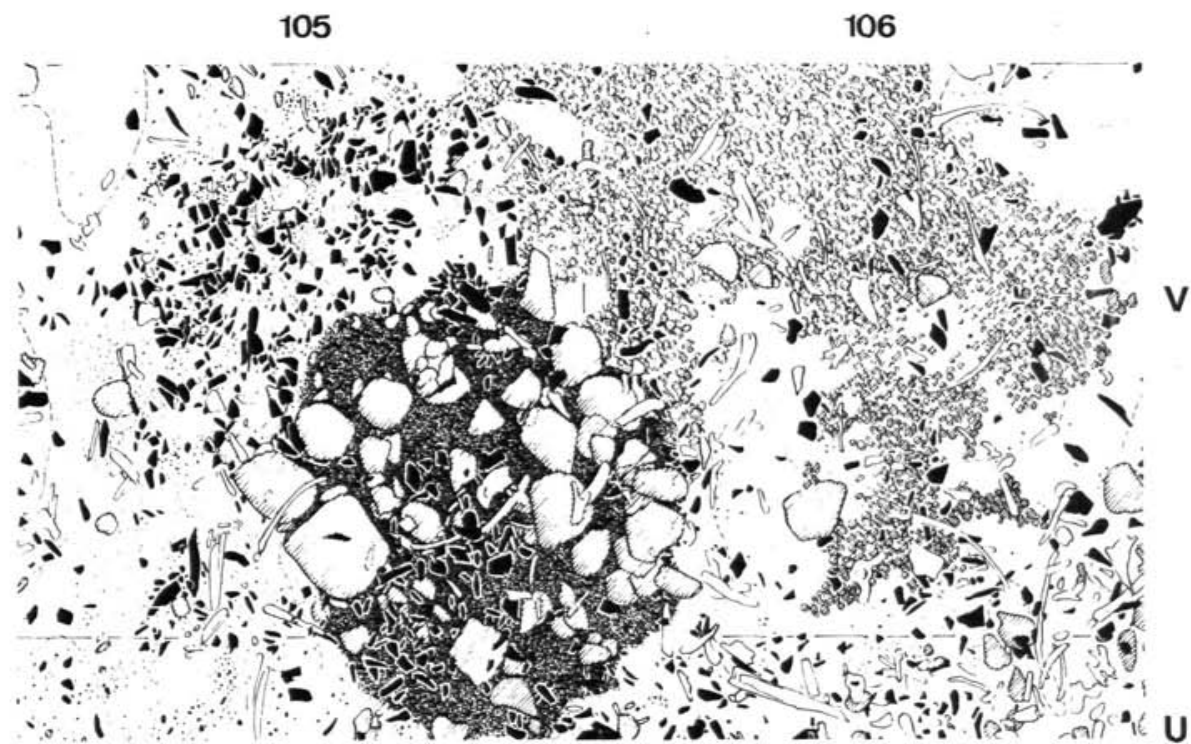

Detalle dibujado, en escala más pequeña, de la fotografía superior. Fuente: A. Leroi-Gourhan, y M. Brezillon, Fouilles de Pincevent.

en el mismo estómago de la presa o víctima objeto del cocido, añaden agua y prenden debajo un fuego utilizando huesos que arden muy bien; el estómago contiene la carne ya separada de los huesos. De esta forma, una res puede ser cocinada con sus propios despojos. Esta noticia transmitida, como se ha dicho por Herodoto, es muy parecida a otra procedente de América del Norte, y que debemos a Driver y a Massey (1957): “En la región subártica y regiones adyacentes así como entre los Omaha, Alabama y Comanche, las panzas de las reses (alee y caribu) eran suspendidas en un fuego para lograr una cocción directa. Estas panzas podían durar en uso desde varios días a un mes. Lo que es seguro que duraban por lo menos el tiempo suficiente para poder cocer en su interior la carne del animal del que procedía e incluso la de otro que habría de suministrar una nueva panza recipiente». Los citados autores insisten, que era necesario no obstante, manejar la panza con cierto cuidado, asegurándose que el fuego no fuera muy intenso y que el recipiente no fuera lamido o expuesto directamente a las llamas sino a cierta distancia, prefiriéndose por ello colocarla sobre brasas y no sobre un fuego «vivo".

Esa técnica u otras similares pudieron pues ser bien conocidas y utilizadas en todo el Paleolítico del Viejo Mundo. Comprobada experimentalmente su eficacia por algún antropólogo o, se poseen asimismo curiosas experiencias a técnicas culinarias semejantes vigentes en el Medievo de Irlanda y Escocia, junto con otras técnicas de cochura asimilables - que utilizaban a su vez una piel de carnero-, y que han seguido utilizándose en Europa hasta el siglo XVI. 


\section{Final}

Indudablemente podríamos terminar aquí. Una investigación rigurosamente científica, no puede basarse más que en pruebas documentales, fruto de la indagación paleontológica y arqueológica. Por otra parte las hipótesis de trabajo o las teorías más o menos brillantes según dictados de la moda o de intereses acientíficos, que se presentan fulgurantes y chisporroteantes cuan un castillo pirotécnico de fuegos de artificio, no rasgan en manera alguna - mas que en un seudo-alba-, la noche de los tiempos. "Cocinar hizo al hombre» de Faustino Cordón podrá ser un posible bestseller, como otros tantos publicados en una misma o discutible línea. No obstante, por los mismos ámbitos a que tales best-sellers van destinados - y que en este caso concreto sabemos que es de "gastrónomos y estudiosos del arte culinario" (pág. 103)-, y que difieren del que es dominio del conocimiento científico, sirve ya para definirle y calificarle negativamente.

Así, y por otra parte y sin entrar demasiado en materia en el mismo se presentan también como dogmas irrefutables, cosas de las que todavía en 198 apenas sabemos, como por ejemplo si - dejando al margen las metáforas-, el primate del que desciende el hombre tuvo una vida anterior arborícola, antes de bajar al suelo y adoptar la postura erecta e incluso instalarse en la sabana. Apenas sabemos si los útiles que hizo suyos aparecieron en su existencia como realmente piensa Cordon (pág. 71 y ss.), o más bien pudieron surgir como imaginan conspicuos especialistas en esta campo concreto como pueden ser pongamos por caso los franceses Bordes, Tixier, Roche, Chavaillón... los anglosajones Leakey, Evans, Oakley... los hispanos Querol, Santonja... y cuyos trabajos ignora olímpicamente, al igual que planteamientos de ecólogos de conocido prestigio, por no hablar de los estudiosos como M. Sahlins... Cordon se complace en insistir en una vida "paleolítica", en "hordas", sin tener en cuenta que la voz o término "horda" aplicada a la investigación etnológica no se utiliza desde hace muchos lustros y desde que muchas de las teorizaciones de Atkinson, Spencer, Darwin, Morgan, Marx y Engels fueron paradas por el tamiz del rigor científico. Por otra parte es necesario subrayar que se carece de bases científicas no sólo para afirmar tajantemente que la aplicación de útiles - cual fuera su material-, abrió al homínido la ruta hacia el autotrofismo. Mas, si tenemos en cuenta que en el caso concreto de nuestra especie el autotrofismo se presenta como connatural no sólo a una particular dentición como han podido probar Clifford Jolly y Washburn entre otros, los primeros australopithecinae y hominidae conocidos (de muy posible régimen omnívoro), sino tambień a un concreto sistema societario. Tampoco existe evidencia científica alguna -mas tras muy recientes trabajos-, para poder afirmar que el origen del lenguaje - «la palabra humana" (?), se explica Cordon-, fuera anterior a la conquista del fuego o de las técnicas culinarias, ni mucho menos para dogmatizar que "el cambio de circunstancias que supuso el hecho de acampar para transformar por el fuego alimento ajeno en alimento propio permitió el surgimiento de la palabran (pág. 101), tanto más cuando sabemos que la "comunicación simbólica" existe no sólo en el mundo humano, sino también en otros (ahí está pongamos por caso la "danza» de las abe- 
jas, impartiendo información a sus congéneres en torno a fuentes de alimento y recolección). Podríamos señalar también que en el Paleolítico donde se sitúan los más remotos orígenes conocidos del cocinado y guisado, no pueden situarse aportaciones tales como la agricultura y la ganadería (pág. 123), que pertenecen a otro horizonte cultural o etapa evolutiva siguiente, significarse tras un ambiente neotermal (postglacial), con el conocimiento de la cerámica y los recipientes hechos de barro cocido, inventados ya tardíamente hacia el 9.000 B. P. si hacemos caso de concretas determinaciones cronológicas. También que el "disfrute gastronómico" (pág. 133) sólo surge al considerar la cocina o el guisado como un arte, más que una necesidad alimentaria, y eśte sólo puede concebirse como una realización plenamente lograda en culturas ya históricas del Creciente Fértil y no antes, como ocurre con otras adquisiciones que hicieron nacer ese mundo que los griegos imputaron a la tekné propiamente dicha elevada a epifanía y cuya calibración corresponde a la Estética. Pensar otra cosa sería pura e inútil lucubración, que no puede permitirse un pensador que desconoce la bibliografía más reciente sobre un concreto campo y que por lo que sabemos no se ha molestado demasiado en discurrir por los laberintos de un incierto asado que empezó quizá a ser registrado en el libro de la tierra hace más de esos millones de años, cuando el primer fuego controlado sirvió a un primate progresivo - quizá por primera vez en nuestra galaxia-, para vislumbrar la posible trascendencia del destino de su especie.

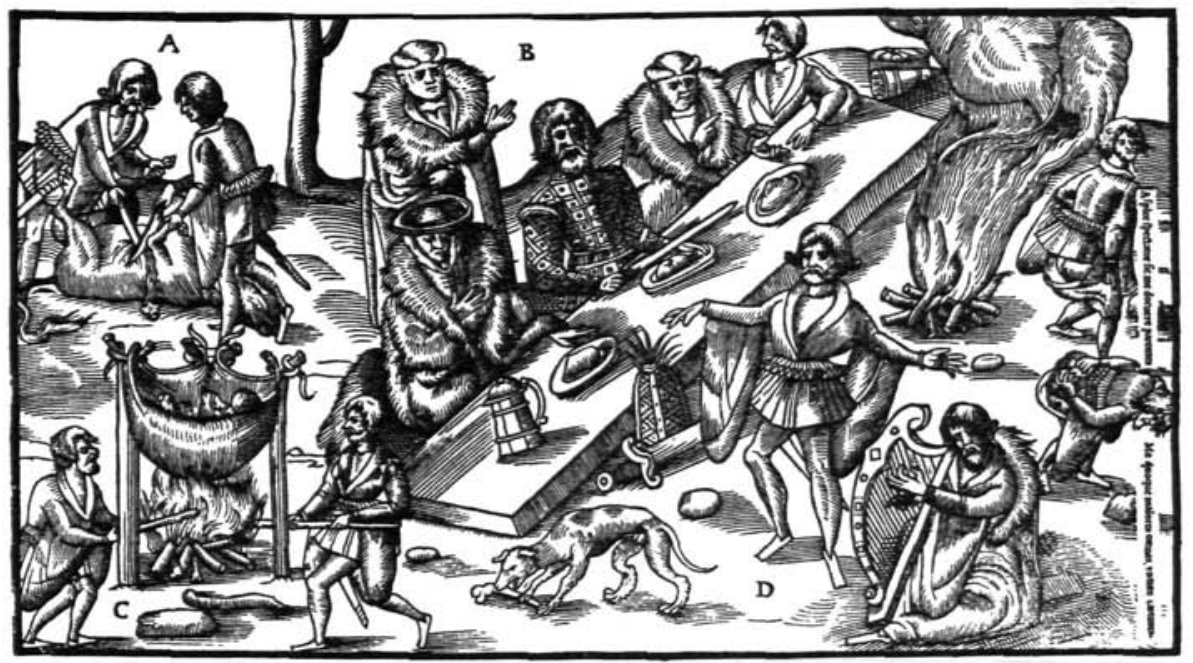

Xilografia que figura en The Image of Ireland, de John Derrick (1581), representando a unos señores del país, durante la celebración de un festín. Obsérvese la importancia que se otorga, junto a un bardo, un arpista y varios juglares, a un par de matarifes que preparan la res para el banquete (A), pero también a los cocineros (C), que de acuerdo con una ancestral técnica culinaria cuyos orígenes se remontan a la Prehistoria, cuecen la carne, utilizando como contenedor de circunstancias, el mismo pellejo de la res, mantenido sobre el fuego a una distancia que impide su destrucción, mediante tres postes ahorquillados, de los que pende aquel. 


\section{Bibliografía sumaria}

Aguirre, E.; Butzer, R.: Howell, F. Clark: "Noticia preliminar sobre el emplazamiento acheulense de Torralba (Soria)». Excavaciones arqueológicas en España, vol. 10, 1963, 38 págs.

Almagro BaSch, M.: «Los omoplatos decorados de la cueva de El Castillo, Puente Viesgo, Santander». Trabajos de Prehistoria, vol. 33, págs. 11-100. Madrid, C.S.I.C., 1976.

Arambourcu, R. et Jude, P.: "La conquête du feu au Paléolithiquen. Bull. de la Soc. d'Et. et Rech. Préhist., les Eyzies n. ${ }^{\circ}$ 5, págs. 16-19, 1955.

Bodenheimer, F. S.: Insects as Human Food, La Haya, 1951.

Brothwell, D. R.: "The in earlier human populations", en Proceedings of the Nutrition Society, 18, págs. 59-65, 1959.

Brothwell, D. R. y Higgs, E. S. (Eds.): Science in Archaelogy, Londres, 1963 (hay una edición en castellano publicada en México por F. C. E. 1980).

BORDAZ, J.: Tools of the Old and New Stone Age, Londres, 1970.

BOONE, Y.: "Le ramassage des coquillages" "La Prehistoire Française I, París, CNRS 1976, págs. 703-707.

BORDES, F.: Cf. recensión al artículo de K. P. Oakaley "Fire as a Paleolithic Tool and Weapon». L'Anthropologie, tomo 61, 1957 (1958), fasc. 3-4, págs. 314-317.

BreuIL, H.: Le Feu et l'industrie de pierre et d'o dans le gisement du "Sinanthropus" Chou-Ku-Tien, L'Anthropologie tomo 42, 1932, págs. 1-17.

De CASTro, J:: Geography of Hunger, Londres, 1955 (hay edición española).

Callen, E. y Cameron, T. W. M.: "A prehistoric diet reveaved in coprolites" en New Scientist, 8, 1960, págs. 35-40.

Claudian, J.: "Propositions pour l'analyse du comportement alimentaire del l'Hommen, I Conf. Recontre Intern. P.I.P.A.L., París, 1964, pág. 69.

DELPECH, F y Rigaud, J. PH.: "Etude de la fragmentation et de la repartition des restes os eux dans un niveau d'habitat paléolithique», Table ronde sur l'industrie de l'os dans la Préhistoire, Sénanque, 1974, mimiografiado.

Dimbleby, G.: Plants and Archaeology, Londres, Paladín/Granada, 1978.

Chaney, R. W.: "The food of Peking Man" en Carnegie Institution of Washington New Service Bulletin, III, 1935, págs. 199-202.

CORDON, F.: Cocinar hizo al hombre, Barcelona, Tusquets, 1980, (3. a ed. 1981).

DrIVER, H. E. y MASSEY, W. C.: "Comparative Studies of North American Indians", Trans. of the Amer. Philos Soc., n.s., vol. 47, 1957, págs. 228-233.

FORBES, R.: Studies in Ancient Technology, vols. II y III, Leiden, 1955.

Frazer, J. G.: Mythes sur l'origine du feu, París, Payot, 1969 (hay edición española, Buenos Aires).

GARINE, IGOR DE: "The Sociocultural aspects of nutrition", Ecology of Food and Nutrition, I, 1943-63/1972.

Gómez-Tabanera, J. M.: En torno a la ecología del Asturiense». Actas del XII Congreso Nacional de Arqueología, Zaragoza, 1976.

GÓMEZ-TABANERA, J. M.: "Sobre alimentación humana durante el post-glacial en la cornisa astur-Cantábrican. Cuadernos de Prehistoria y Arqueologia Castellonenses, 4, Castellón de la Plana, 1957.

Gómez-Tabanera, J. M.: "La caza en la Prehistoria. Asturias, Cantabria, Euskal-Herria. Madrid, Ed. Istmo, 1980.

GouRev, G.: Darwinisme et Religion, Moséu Eds. Lang. etrangères, 1960.

HAMARD, A.: "Brèves notes sur l'interpretation des cercles de pierres entourant certains foyers". Bull. de la S. P. F, tomo LI, fasc. 11-12, págs. 524-528, 1954.

HARRIS, M.: Canibales y Reyes (trad. esp.), Barcelona, Argos-Vergara, 1978.

HARRIS, M.: Introducción a la antropologia general (trad. esp.), Madrid, Alianza, 1981.

HarroY, J. P.: La economía de los pueblos sin maquinismo, Madrid, Guadarrama, 1973. 
Leroi-Gourhan, A.: Seminaire sur les structures d'habitat. Temoins de combustion. College de France. Chaire de Prehistoire, 1973 (mimiografiado).

Levi-Strauss, C.: Le Cru et le Cuit. Mythologiques, París, Plon, 1964 (hay ed. española, F.C.E., México).

LUMLEY, M.: Une cabane acheuléenne dans la grotte au Lazaret, Mem. de la S., tomo 7, 1969, pág. 234.

Moreno Navarro, I.: Cultura y Modos de Producción. Bilbao, Ed. Nuestra Cul., 1978.

OAKLEY, K. P.: Evidence of fire in Sout African Cave deposits, Nature, tomo 17, 1954, pág. 261.

OAKLEY, K. P.: Fire as a Paleolithic Tool and Weapon, Proc. of the Prehist., vol. XXI, 1955, págs. 36-47.

OAKLEY, K. P.: "L'utilisation du feu par l'Homme». En Les processus de l'hominisation, París, C.N.R.S. 1958, págs. 135-145.

OAKLEY, K. P.: «Use of fire by Neandertal Man and his Precursors", en Neandert, Ed. du Centenaire, Utrecht, 1958, págs. 267-269.

OKaleY, K. P.: “On Man's Use of Fire, with Comments on Tool-Making and Huntin. En Social Life of Early Man, S. Washburn Ed. Viking Funds Publications in Anthropology, vol. 31, 1961, págs. 176-193.

OAKLEY, K. P.: Possible Origins of the Use of Fire, Man, 1961, págs. 207.

Obermaier, H.: El hombre fósil (1. ${ }^{\mathrm{a}}$ ed.). Com. Inv. Paleon. y Preh. Mem., 9, Madrid, 1916.

Perles, C.: Prehistorire du feu, París, Massón, 1977.

RADOLIFFE, W.: Fishing from the Earliest Times, Londres 1926.

RYLER, M. L.: "Paunch Cooking», Antiquity, vol. XLIII, 1969 n. 171, pág. 218.

Roche, H.: Premiers Outils Taillés d'Afrique, París, Soc. d'Ethnographic, I.

SANTAMARIA, D.: Los australopitecidos de Sudáfrica, I.N.A.E., México, 1978.

Semenov, S. A.: Prehistoric technology, Londres, Cory, Adams and Macky, 1964 (Ed. española: Madrid, Akal, 1981).

STEWART, O. C.: "Fire as the First Great Force emb loyec by Man». Man's Role Changing the Face of the Earth, Ed. W. L. Thomas, Chicago, 1956.

THEOBALD, D.: Fondements geologiques de la Prehistoire. Essai de chronostratigraphie des formations quaternaires, París, Doin, 1972.

VAUFREY, R.: “Un usage actual des pierres chauffées”, L'Anthropologie, tomo 54, 1951, n. . 5-6, págs. 546-547.

WASHburn, S. L.: Social Life of Early Man, Aldine, Chicago, 1961.

WHITE, T. E.: "Obersvations on the butchering technique of some aboriginal poeples", en American Antiquity, 17, 1952, 337-8; 19, 153, 160-4; 19, 1954, 254-64; 21, 1955, 170-8.

WATSON, L.: El mono omnívoro, Barcelona, Plaza y Janés, 1973. 